\title{
Leptospira infections in trappers from Ontario
}

\author{
Bryna Warshawsky MDCM${ }^{1}$, L Robbin Lindsay $\mathrm{PhD}^{2}$, Harvey Artsob $\mathrm{PhD}^{2}$
}

\author{
B Warshawsky, LR Lindsay, H Artsob. Leptospira infections in trappers from Ontario. Can Infect Dis \\ $2000 ; 11(1): 47-51$.
}

BACKGROUND: Four trappers presented to the Middlesex-London Health Unit in November, 1997 with similar clinical presentations. All four complained of fever, chills and headache, and three of the four had severe muscle aches. All gave histories of trapping raccoons before the onset of illness. Three of the four men exhibited diagnostic seroconversions to Leptospira grippotyphosa.

OBJECTIVE: To describe the four suspected cases of leptospira infections and to determine whether raccoons might serve as a reservoir of infection using field studies.

DESIGN: Raccoon serology were undertaken using the microscopic agglutination test against eight serovars of Leptospira interrogans including L grippotyphosa. Raccoons were trapped using Tomahawk live traps, anaesthetized with intramuscular injection of ketamine and acepromazine, bled by cardiac puncture and released.

RESULTS: Forty-two raccoons were trapped in Middlesex $(n=36)$ and Kent counties $(n=6)$ from April 25 to May 2, 1998, and $10(23.8 \%)$ of these animals had antibodies to L grippotyphosa.

CONCLUSIONS: Infections due to L grippotyphosa or a closely related serovar are a risk for trappers in Ontario, and raccoons are a likely reservoir of this bacterium.

Key Words: Grippotyphosa; Leptospirosis; Ontario; Raccoons; Trappers

\section{Infections à Leptospira chez des trappeurs de l'Ontario}

HISTORIQUE : Quatre trappeurs se sont présentés à l'unité sanitaire de Middlesex-London en novembre 1997 avec des tableaux cliniques semblables. Ils se plaignaient tous les quatre de fièvre, de frissons et de céphalées; trois d'entre eux souffraient de douleurs musculaires intenses. Ils ont tous mentionné avoir trappé le raton-laveur avant le déclenchement de la maladie. Trois des quatre hommes présentaient des signes de séroconversion diagnostique à Leptospira grippotyphosa.

OBJECTIF : Décrire les quatre cas d'infection soupçonnée d'être à Leptospira et, par le biais d'études menées sur le terrain, déterminer si les ratons-laveurs peuvent avoir servi de réservoirs infectieux.

MODÈLE : La sérologie des ratons-laveurs a été entreprise à l'aide d'un test d'agglutination au microscope contre huit sérovars de Leptospira interrogans, y compris L. grippotyphosa. Les ratons-laveurs ont été trappés à l'aide de trappes de type Tomahawk, anesthésiés au moyen d'une injection intramusculaire de kétamine et d'acépromazine, ils sont subi un prélèvement par ponction cardiaque, puis ils ont été relâchés.

RÉSULTATS : Quarante-deux ratons-laveurs ont été trappés dans les comtés du Middlesex $(n=36)$ et Kent $(n=6)$ entre le 25 avril et le 2 mai 1998 et dix (23,8\%) de ces animaux étaient porteurs d'anticorps dirigés contre L. grippotyphosa.

CONCLUSIONS : Les infections dues à L. grippotyphosa ou impliquant un sérovar fortement apparenté constituent un risque pour les trappeurs de l'Ontario et les ratons-laveurs sont susceptibles d'héberger ces bactéries.

$\mathrm{L}$ eptospirosis is a bacterial disease that affects most mammals throughout the world (1). The causative agent of leptospirosis, Leptospira interrogans, has many serovars, several of which have been isolated in Canada. Although these se- rovars have been shown to infect many species of wild and domestic animals, human infection occurs only rarely.

Human infection has primarily been considered to be an occupational hazard affecting farmers, abattoir workers and

${ }^{1}$ Middlesex-London Health Unit, London, Ontario; ${ }^{2}$ Bureau of Microbiology, Canadian Centre for Human and Animal Health, Winnipeg, Manitoba

Correspondence and reprints: Dr B Warshawsky, Middlesex-London Health Unit, 50 King Street, London, Ontario N6A 5L7. Telephone 519-663-5317 ext 2427,fax 519-663-8241,e-mail bryna.warshawsky@mlhu.on.ca 
others whose occupations involve contact with animals (1). However, recreational activities such as swimming, canoeing, kayaking, biking, and hunting, and contact with pet dogs, domesticated livestock, rodent infestation and rainwater catchment systems in household environments have recently been identified as additional risk factors (2). A large outbreak of leptospirosis occurred in athletes participating in a triathlon in Illinois in the summer of 1998 , likely linked to swimming in Lake Springfield (3).

In 1997, three confirmed and one suspected case of leptospirosis were recognized in trappers in Middlesex County, Ontario. Presumptive evidence suggested possible transmission to the trappers via contact with raccoons. This paper describes the clinical presentation and laboratory findings of these four individuals and reports studies undertaken to determine whether raccoons in Ontario are infected with $L$ interrogans.

\section{MATERIALS AND METHODS}

Patient serology: Patient sera were tested by the microscopic agglutination test (MAT) against the following serovars of L interrogans: autumnalis, ballum, canicola, grippotyphosa, ictohemorrhagia, pomona, sejroe and tarassovi.

Sera were initially diluted to 1:50 (twofold dilutions thereafter to end-point titre) using phosphate-buffered saline (PBS), and aliquots were placed in multiwelled microtitre plates. Stock cultures of the $L$ interrogans serovars were diluted in PBS to a density of 1 to $2 \times 10^{8}$ leptospiral organisms $/ \mathrm{mL}$. The density of leptospiral organisms to incubate with the serum samples was determined by direct counting using a darkfield microscope (Axioplan 2, Zeiss Microscopes, Jena, Germany) and a density of 100 organisms/field of view at $400 \times$ magnification was used. Equal volumes of dilute serum and leptospiral cultures were mixed in the wells of the microtitre plates and incubated for 2 to $4 \mathrm{~h}$ at $30^{\circ} \mathrm{C}$. These mixtures were then examined at $400 \times$ magnification to establish the degree of agglutination. Samples with greater than $50 \%$ agglutination between live spirochetes and antibody were considered positive at each dilution, and all serum samples were titrated to end-point titres. Negative and positive controls, respectively, consisted of leptospira-negative human serum diluted to $1: 100$ in PBS and leptospira-positive human sera diluted to $1: 400$ in PBS.

Raccoon sampling and leptospira serology: Raccoons were trapped using live traps (No 202, Tomahawk Live Traps, Tomahawk, Wisconsin). Traps were set for seven consecutive nights starting on April 25, 1998, and were baited with sardines, corn and apples. Traps were usually set between 1400 and $1800 \mathrm{~h}$, and checked the following morning between 0600 and $0800 \mathrm{~h}$. Captured raccoons were anaesthetized with intramuscular injections of $25 \mathrm{mg} / \mathrm{kg}$ of body weight of ketamine and $0.1 \mathrm{mg} / \mathrm{kg}$ of acepromazine. The weight, sex and age (adult or juvenile) of each captured animal were recorded. Blood samples were collected by cardiac puncture using $3.8 \mathrm{~cm} 22$ gauge needles. Blood was centrifuged at $5000 \mathrm{rpm}$ for 10 to 20 mins, serum from each sample was removed, placed in $2 \mathrm{~mL}$ cryovials (Sarstedt, Numbrecht, Germany) and frozen at $-70^{\circ} \mathrm{C}$. Raccoon sera were tested by MAT as described previously. Sera were ini- tially screened against Leptospira grippotyphosa only. Reactive sera were subsequently titrated against all eight serovars noted previously.

\section{RESULTS}

Case reports-Patient 1: On November 3, 1997, a 37-year-old male lacerated his left thumb while skinning a raccoon. This laceration required sutures. On November 7, 1997, he developed a fever, chills, joint and muscle aches, especially in his shoulders and lower back, a stiff neck, and severe bifrontal headaches with some dizziness. He presented to the emergency department on November 12, 1997, where aside from a fever, mild cough and slight yellowish tinge to his skin, no abnormalities were noted. Specifically, conjunctival injection, nuchal rigidity and abdominal tenderness were not found.

Results of hematological, biochemical and urinalysis laboratory tests are summarized in Table 1 . Cerebral spinal fluid (CSF) examination was normal on biochemical analysis and microscopy. There was no growth on cultures from his CSF, throat or urine. Abdominal ultrasound and chest x-ray were unremarkable.

The patient received pain medication and muscle relaxants, and was feeling well enough by November 17, 1997 to be discharged from the hospital. He did not note a biphasic pattern to his illness.

Laboratory testing revealed no evidence of an acute viral illness, $Q$ fever or hepatitis B and only a past history of hepatitis A. Leptospira serology revealed a diagnostic seroconversion to the L grippotyphosa serovar (Table 2).

Besides trapping and skinning raccoons, the patient also hunted deer.

Patient 2: On November 20, 1997, a 50-year-old male developed muscle pain across the back of his neck and shoulders that progressed within a day to fever, chills, sweats, anorexia, general malaise, joint pain, headache and a dry cough. He presented to his family physician on November 24, 1997 and was admitted to hospital on November 25,1997 . Physical examination revealed a fever of up to $40.2^{\circ} \mathrm{C}$ and scleral jaundice. No conjunctival injection, heptosplenomegaly or abdominal tenderness were noted. Laboratory test results are presented in Table 1. Abdominal ultrasound and chest X-ray were unremarkable.

The patient was treated on November 25, 1997 with cefoxitin (Mefoxin, Merck Frosst Canada Inc, Kirkland, Quebec) (2 g every $12 \mathrm{~h}$ intravenous) and ciprofloxicin (Cipro, Bayer Inc, Toronto, Ontario) (500 mg by mouth every $12 \mathrm{~h}$ ). Doxycyline $100 \mathrm{mg}$ by mouth twice daily was added on November 26 , 1997, when the diagnosis of leptospirosis was suspected. The patient was afebrile and feeling somewhat better by November 26, 1997, although his headache persisted. He was significantly better by November 27,1997, and gave no history of a biphasic illness. He was discharged on November 28, 1997 on doxycycline $100 \mathrm{mg}$ bid for five additional days and ciprofloxicin $500 \mathrm{mg}$ bid for 12 additional days. Follow-up blood work on December 9, 1997 revealed a normal complete blood count except for an elevated platelet count of $436 \times 10^{9} / \mathrm{L}$ (normal 150 to $400 \times 10^{9} / \mathrm{L}$ ). Conjugated bilirubin and transaminases had re- 
TABLE 1

Results of hematological, biochemical and urinalysis laboratory tests of four patients with suspected leptospira infection

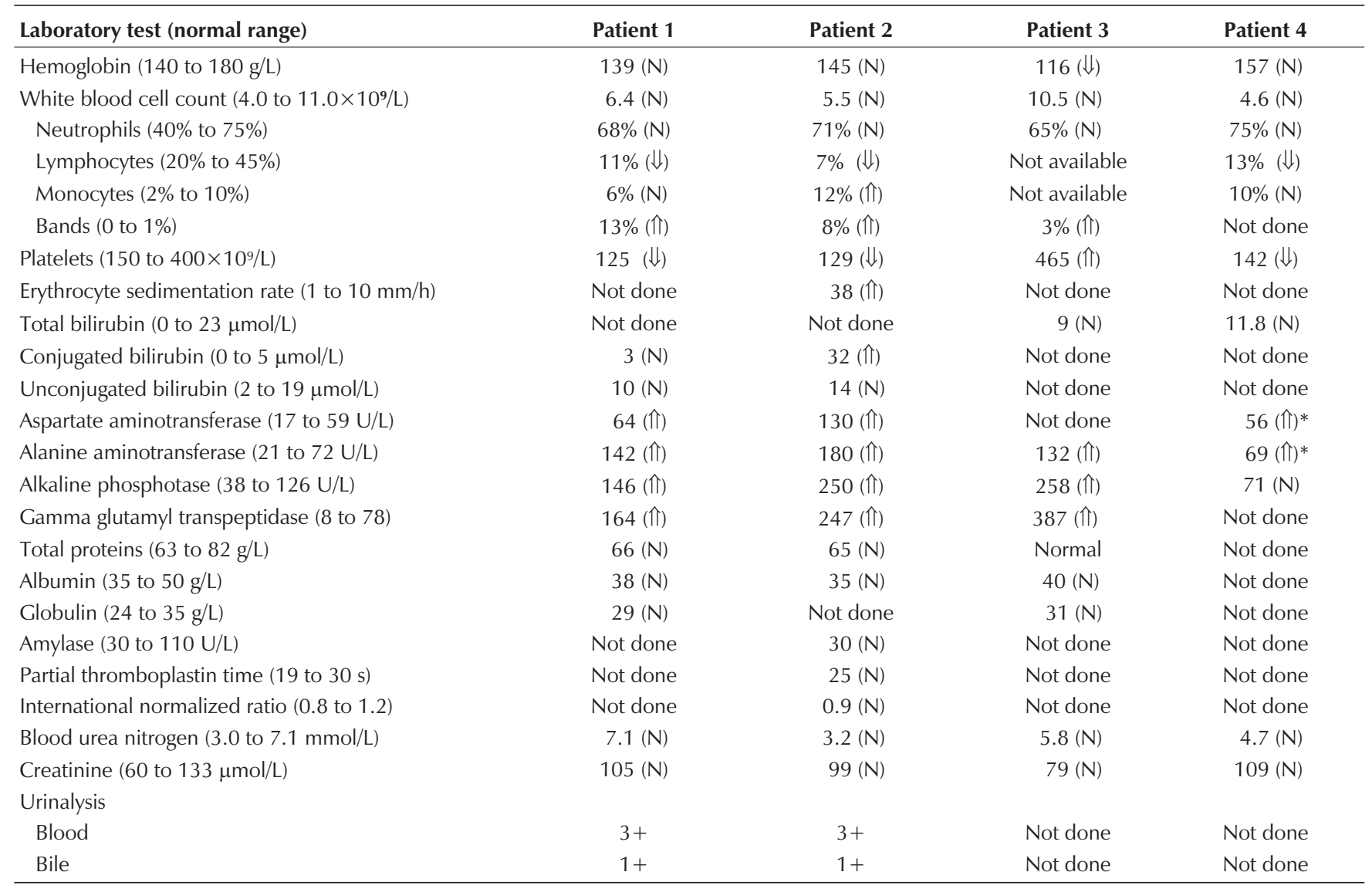

*Patient 4 used a different laboratory with a normal range for aspartate aminotransferase of 6 to $38 \mathrm{U} / \mathrm{L}$ and normal range for alanine aminotransferase of 4 to 42 U/L. $\Downarrow$ Decreases; $\Uparrow$ Increased; N Normal

turned to normal, although his alkaline phosphatase and gamma glutamyl transpeptidase remained slightly elevated.

Laboratory testing was negative for hepatitis B and C, cytomegalovirus, legionella and $\mathrm{Q}$ fever, and showed only a past history of hepatitis A. Leptospira serology revealed a seroconversion to the L grippotyphosa serovar (Table 2).

This patient had been trapping and skinning raccoons in the area west of London since November 1, 1997, and had hunted ducks and geese.

Patient 3: On November 27, 1997, Patient 1 called the Health Unit to report that he knew of another man who was being seen in the local emergency department with similar symptoms. $\mathrm{Pa}$ tient 3 was a 38-year-old male who gave a history of feeling ill since November 20, 1997 with fever, chills, headache, cough, sweats and severe vomiting. The physical examination of patient 3 was within normal limits. Laboratory results are presented in Table 1. Urinalysis was not performed. The patient did not receive any treatment and was not admitted to hospital. He continued to feel ill until December 1, 1997, but did describe a one-day reprieve in his symptoms before visiting the emergency department on November 27, 1997.

Testing to establish the etiology of his symptoms was negative for $\mathrm{Q}$ fever and hepatitis B and C, and showed only a past history of hepatitis A. Leptospira testing revealed a seroconversion to the $L$ grippotyphosa serovar (Table 2).
TABLE 2

Serology of confirmed leptospira cases from LondonMiddlesex, Ontario

\begin{tabular}{lcccc}
\hline Patient & $\begin{array}{c}\text { Date } \\
\text { of } \\
\text { onset }\end{array}$ & $\begin{array}{c}\text { Days } \\
\text { post } \\
\text { onset }\end{array}$ & $\begin{array}{c}\text { Microscopic agglutination test } \\
\text { Leptospira } \\
\text { grippotyphosa }\end{array}$ & $\begin{array}{c}\text { Leptospira } \\
\text { ictohemorrhagia }\end{array}$ \\
\hline 1 & $7 / 11 / 97$ & 6 & $\leq 1: 100$ & $<100$ \\
& & 13 & 3200 & 100 \\
& & 33 & 12,800 & $<100$ \\
2 & 6 & $<100$ & $<100$ \\
& & 19 & 200 & $<100$ \\
3 & $20 / 11 / 97$ & 7 & $<100$ & $<100$ \\
& & 92 & 400 & $<100$ \\
\hline
\end{tabular}

*Results are expressed as reciprocal of titres; ${ }^{\dagger} T$ Tests for the following serovars were negative: Leptospira autumnalis, ballum, canicola, pomona, sejroe and tarassovi

This patient had been hunting raccoons throughout Middlesex County since October 1, 1997. He did not wear gloves while hunting and had several cuts on his hands. He had also been hunting deer. Although patient 3 was known to patient 1 , they did not hunt together.

Patient 4: Patient 4 was identified by patient 2 as having symptoms similar to his own. Patient 4 was a 50-year-old male who developed fever chills, sweats, headache, fatigue, and se- 
vere muscle and joint pain on November 23, 1997. He felt significantly better by November 26, 1997 and did not seek medical attention except to have blood tests taken as requested by the Health Unit (Table 1). Leptospira serology on sera taken up to several months after the onset of symptoms was negative for this clinically suspect patient.

Patient 4 had been hunting raccoons and coyotes for one month before the onset of his symptoms. He hunted in the area west of London. He reported always having nicks on his hands and did not wear gloves when handling animals. Patients 4 and 2 were friends but did not hunt together.

Active surveillance was initiated to detect other human cases. Physicians in Middlesex-London, and health units and trappers in Ontario were notified of the possibility of acquiring leptospirosis from raccoons. Physicians and medical officers of health were asked to report suspected cases. To date, no further cases have been identified.

Raccoon sampling and leptospira serological results: Between April 25 and May 2, 1998, 42 raccoons were trapped, including 36 from five different locations in southwestern Middlesex County and six from Rondeau Provincial Park in neighboring Kent County. All animals were adults (19 males and 23 females) with average weights of $6.1 \pm 1.4 \mathrm{~kg}$ and $5.1 \pm 1.4 \mathrm{~kg}$, respectively.

Ten of the 42 raccoons $(23.8 \%)$ tested positive to the $L$ grippotyphosa serovar. Infected raccoons were identified from all six locations with positive rates ranging from $16.7 \%$ to $40 \%$. Most raccoons that tested positive to the $L$ grippotyphosa serovar had titres of 1:50; however, titres as high as 1:200 were observed in one animal. Equal numbers of males and females had evidence of infection with $L$ grippotyphosa or a closely related serovar. Sera from the animals that tested positive against the $L$ grippotyphosa serovar did not react with any of the other serovars of leptospira tested.

\section{DISCUSSION}

Leptospirosis may be manifested in two clinical presentations, anicteric leptospirosis and icteric leptospirosis. Anicteric leptospirosis classically causes two phases of illness, the septicemic phase and the immune phase. The septicemic phase is characterized by fever, chills, headache and severe myalgia that last three to seven days. Patients often experience no symptoms for a day or two and then enter the less severe immune phase of their illness. This phase manifests as fever and headache that can last from four to 30 days. Icteric leptospirosis (also known as Weil's syndrome) is a more severe form of the disease that presents as hepatic and renal dysfunction, hemorrhage and circulatory collapse. Icteric leptospirosis can be fatal in $5 \%$ to $10 \%$ of cases (1).

None of the patients in this cluster had the severe form of leptospirosis, although all had some abnormalities in liver function and two had microscopic hematuria. Only one reported the classic biphasic illness. Conjunctival injection, a common finding in some studies (4), was not noted in any patient. Three of the four patients had mildly depressed platelets, and two had elevated bands on their complete blood count. The duration of illness ranged from three to 11 days, with an average of eight days. The incubation period was impossible to determine accurately because the raccoon exposures occurred over several weeks.

Although patient 4 was not serologically confirmed as a case, his clinical picture and laboratory findings were similar to, but milder than, patients 1, 2 and 3. His illness lasted only three days. It is possible that he was infected but cleared the spirochete before mounting an immune response. Patients 1, 2 and 3 were all seronegative six to seven days after the onset of symptoms.

Leptospirosis developed in these trappers during raccoon hunting season, which extends from October to February. Hunters can trap and skin hundreds of raccoons during this time. All four men reported not wearing gloves when skinning the raccoons. Patient 1 cut himself while skinning a raccoon and required stitches, and patients 3 and 4 reported nicks on their hands. These open lesions were likely the portals of entry for leptospira from infected raccoons. Because leptospirosis can be asymptomatic or present with only mild influenza-like symptoms, it is possible that other trappers have also become infected in Middlesex-London and surrounding areas but have not been diagnosed.

Published studies in Ontario from the 1960s and 1980s reported evidence for the circulation of $L$ interrogans serovars grippotyphosa, hardjo, icterohemorrhagine, pomona, bratislava and sejroe in cattle, deer, dogs, groundhogs, horses, raccoons and skunks (5-11). L grippotyphosa was not a prominent serovar in these studies and was not documented in Ontario raccoons.

The $L$ grippotyphosa serovar has become more prevalent in North America in the 1990s. It has recently been identified as the cause of over 200 cases of leptospirosis in dogs in Long Island, New York (12). The source of transmission to these dogs is likely wildlife species, such as raccoons, skunks, opossums and possibly rats. In Ontario, during 1996 and 1997, six leptospira infections were recognized in dogs, most likely due to the L grippotyphosa serovar (Dr John Prescott, Ontario Veterinary College, personal communication). Thirty of the 70 affected triathletes who underwent enzyme-linked immunosorbent assay testing in Illinois were found to be positive for leptospirosis. Of these 30 athletes, 24 tested positive by confirmatory MAT with highest titres to serovars $L$ grippotyphosa, Leptospira bratislava and Leptospira djasiman (3).

Serological evidence from our study points to the infection of the trappers and raccoons with $L$ grippotyphosa or a closely related serovar. Confirmation that $L$ grippotyphosa was the infecting serovar requires actual isolation and identification of the spirochete, which was not achieved in this study.

The trappers who tested positive, the dogs with leptospirosis in Ontario and New York, and the significant prevalence of the $L$ grippotyphosa reactors in the raccoon population suggest the potential for additional infections. Several measures should be considered to prevent the spread of this zoonotic infection to humans and domestic animals. Trappers should be warned of the importance of wearing gloves while skinning raccoons or handling any wild animal. Other high risk groups who handle animals, such as veterinarians, and animal and 
pest control officers, should receive similar warnings. As well, the general public should be warned to avoid contact with raccoons, and to wear gloves and use bleach when cleaning up areas contaminated with raccoon urine and feces.

Physicians should be alert to the diagnosis of leptospirosis, especially in patients who have been exposed to wild animals. Veterinarians should consider the diagnosis in dogs and other animals that present with compatible clinical signs. Public health officials should consider making leptospirosis a reportable condition to aid detecting, monitoring and controlling potential human outbreaks.

Another public health intervention that may need to be considered is keeping dogs away from areas where children play or swim. Because of the possibility of urine from infected wildlife contaminating stagnant bodies of water, it may also be prudent to avoid swimming and other recreational activities in stagnant ponds and slow flowing streams.

ACKNOWLEDGEMENTS: The authors acknowledge the assistance of Dr Graham Pollett, Medical Officer of Health for Middlesex-London for reviewing the manuscript and Dr John Prescott, Ontario Veterinary College for providing information on canine leptospirosis in Ontario.

\section{REFERENCES}

1. Farr RW. Leptospirosis. Clin Infect Dis 1995;21:1-8.

2. Martone WJ, Kaufmann AF. Leptospirosis in humans in the United States. J Infect Dis 1979;140:1020-2.

3. Update: Leptospirosis and unexplained acute febrile illness among athletes participating in triathlons - Illinois and Wisconsin, 1998. MMWR Morb Mortal Wkly Rep 1998;47:673-6.

4. Kelly PW, Leptospirosis. In: Gorbach SL, Bartlett JG, Blacklow NR, eds. Infectious Diseases, 2nd edn. Toronto: WB Saunders, 1998:1580-7.

5. Abdulla PK, Karstad L, Fish NA. Cultural and serological evidence of leptospirosis in deer in Ontario. Can Vet J 1962;3:71-8.

6. McGowan JE, Karstad L. Field and laboratory studies of skunks, raccoons and groundhogs as reservoirs of Leptospira pomona. Can Vet J 1965;6:243-52.

7. Tabel H. Local production of antibodies to Leptospira pomona in kidneys of chronically infected skunks (Mephitis mephitis). J Wildl Dis 1970;6:299-304.

8. Kingscote BF. The diagnosis of Leptospira serovar hardjo infection in cattle in Canada. Can Vet J 1985;26:270-4.

9. Prescott JF, Miller RB, Nicholson VM. Isolation of Leptospira hardjo from kidneys of Ontario cattle at slaughter. Can J Vet Res 1987;51:229-31.

10. Kitson-Piggot AW, Prescott JF. Leptospirosis in horses in Ontario. Can J Vet Res 1987:51:448-51.

11. Prescott JF, Miller RB, Nicholson VM, Martin SW, Lesnick T. Seroprevalence and association with abortion of leptospirosis in cattle in Ontario. Can J Vet Res 1988:52:210-5.

12. Anonymous. Leptospirosis cases rising in the United States. J Am Vet MEd Assoc 1998:212:472. 


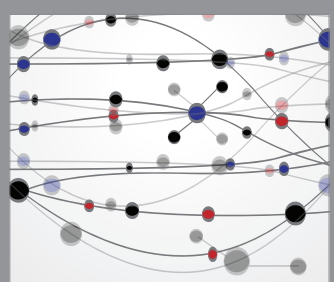

The Scientific World Journal
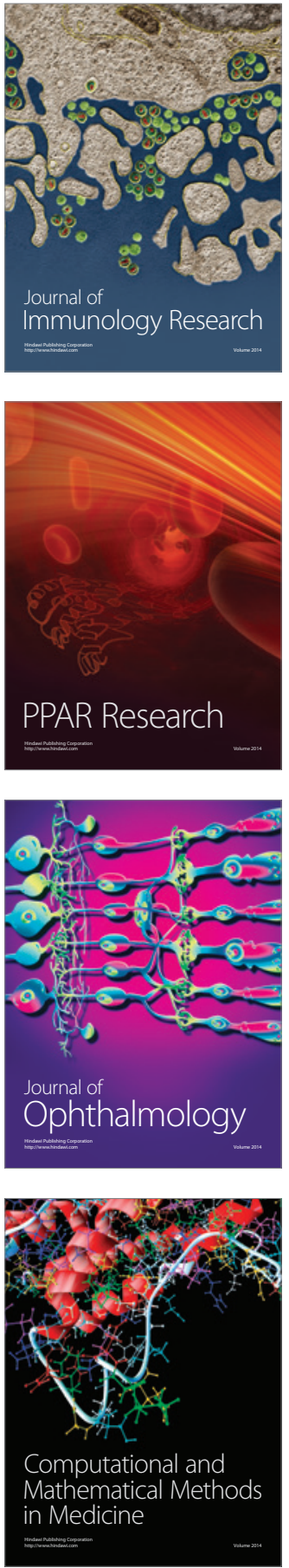

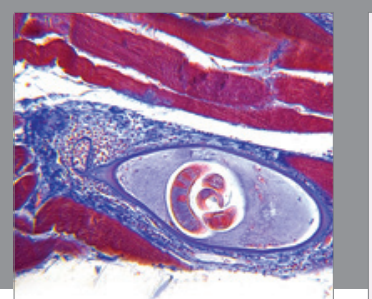

Gastroenterology Research and Practice

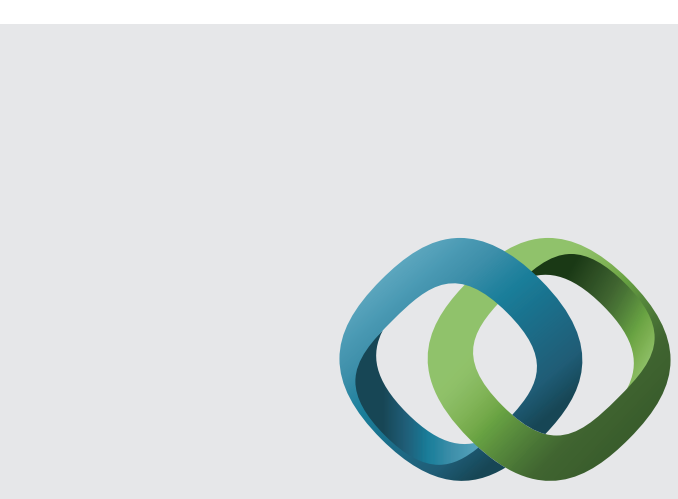

\section{Hindawi}

Submit your manuscripts at

http://www.hindawi.com
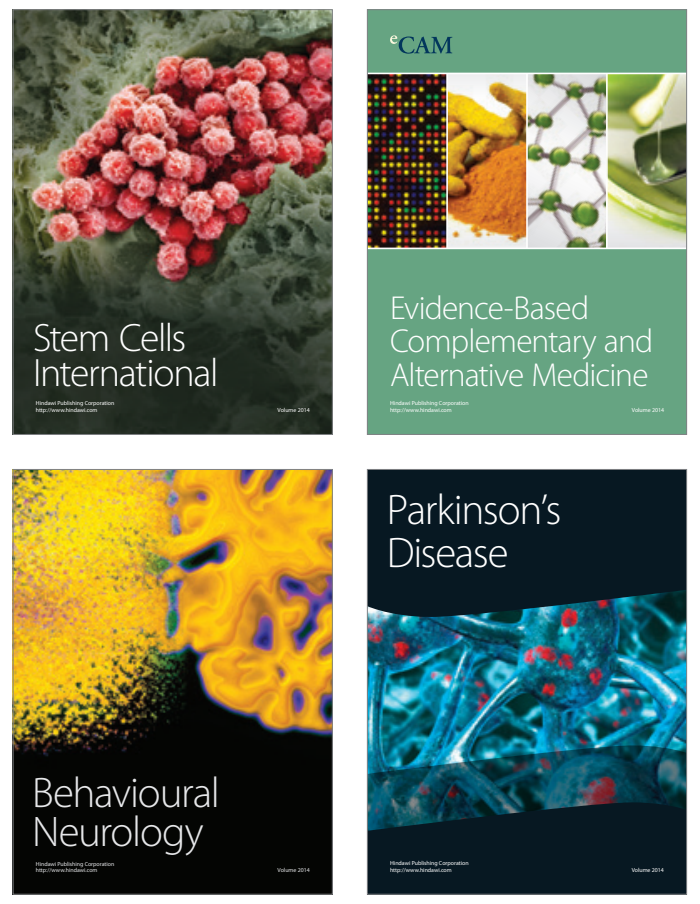
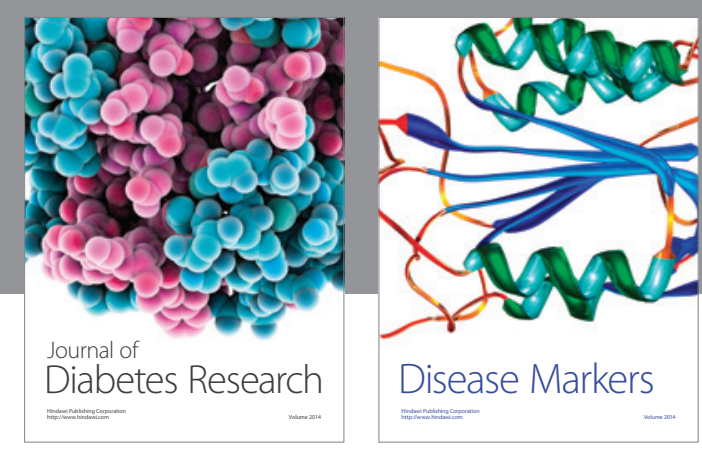

Disease Markers
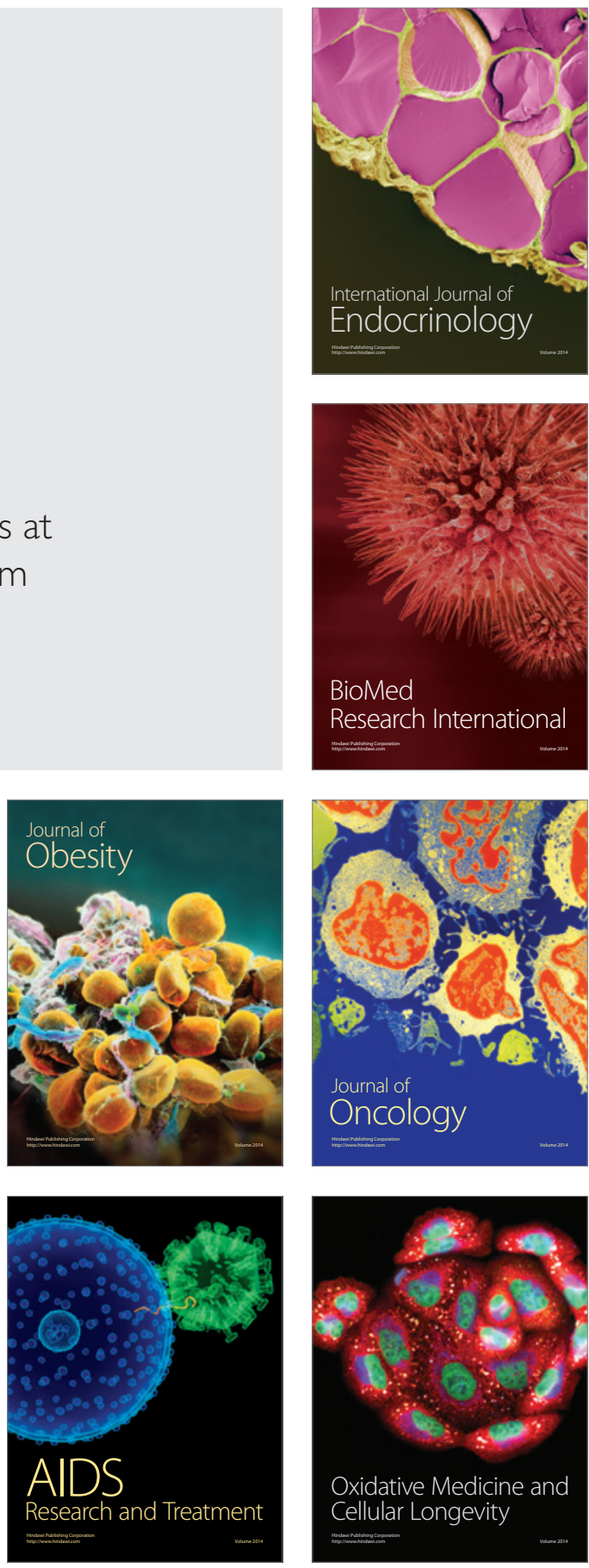